\title{
Bebek dostu bir hastanede doğumu takiben formül süt desteği verilmesinde belirleyici faktörler
}

\author{
Determinant factors in formula supplementation following delivery in a baby-friendly \\ hospital
}

\author{
Selma Aktaş, Ebru Kazancı, Ayşe Korkmaz, Zeliha Özge Kuroğlu
}

Gönderilme tarihi: 10.10 .2019

Kabul tarihi: 10.12.2019

Özet

Amaç: Hayatın ilk 6 ayında sadece anne sütü önerilmesine rağmen, tüm dünyada hastanede formül süt desteği oldukça yaygındır. Bu durumun anne sütü ile beslenme süresinin daha kısa olmasındaki en güçlü belirleyici faktör olduğu farklı çalışmalarda gösterilmiştir. Çalışmamızda bebek-dostu hastanemizde doğum sonrası hastane takiplerinde formül süt desteği gereksiniminin nedenlerini belirlemeyi amaçladık.

Gereç ve yöntem: Bu retrospektif kohort çalışmaya Ocak-Aralık 2018 tarihleri arasında doğum yapan 503 anne ve onların bebekleri dahil edildi. Anne-bebek dosyalarından toplanan bilgiler hastanede formül süt desteği ilişkili faktörleri belirlemek için analiz edildi.

Bulgular: Hastanede yenidoğanların \%14,5’i formül süt desteği aldı. En sık nedenler anne sütü eksikliği (\%78) ve hipoglisemiydi (\%15). Formül süt en sık fincan $(\% 91,78)$ ile verildi. Düşük gebelik yaşı (GY) ve doğum ağırığı (DA), sezaryen doğum (C/S), in vitro fertilizasyon (IVF) gebelik ve kardeşlerin emzirme süresinin daha kısa olması hastanede formül süt desteği alanlarda anlamlı yüksekti. Univariate analizlerde hastanede formül süt desteği ile ilişkili bulunan faktörler lojistik regresyon analizi ile değerlendirildiğinde düşük DA, C/S doğum ve IVF gebeliğin anlamlılığını sürdürdüğü görüldü.

Sonuç: Çalışmamızda hastanede formül süt destek gereksinimini arttıran nedenler düşük DA, C/S ve IVF gebelik olarak belirlendi. Doğumdan önce ve sonra sağlık profesyonellerinin öneri ve desteği, kurumun yazılı emzirme politikası olması doğumdan sonra hastane takipleri sırasında tıbbi endikasyon dışında formül süt desteği verilmemesi düşük DA ve GY ile IVF gebeliğin olumsuz etkilerini azaltabilir C/S ile doğum yapan annelerin emzirmeye başlaması ve devamlılığının sağlanması için daha fazla destek gerekir.

Anahtar kelimeler: Emzirme, anne sütü, hastanede formül süt desteği, formül süt.

Aktaş S, Kazancı E, Korkmaz A, Kuroğlu Z.Ö. Bebek dostu bir hastanede doğumu takiben formül süt desteği verilmesinde belirleyici faktörler. Pam Tıp Derg 2020;13:81-90.

\begin{abstract}
Purpose: Although exclusive breastfeeding is recommended for the first 6 months of life, in-hospital formula supplementation is widespread around the World. It has been shown in different studies that this condition is the most powerful determinant factor of shorter duration of breastfeeding. In our study, we aimed to determine the reasons for the need for formula milk support during postpartum hospital follow-ups in our baby-friendly hospital. Materials and methods: This retrospective cohort study was conducted among 503 mother-infant pairs from January to December 2018. Collected data from mother-infant files were analysed to identify factors associated with in-hospital formula supplementation.

Results: $14.5 \%$ of newborns in the hospital were received formula. The most common reasons for supplementation were lack of human-milk $(78 \%)$ and hypoglycemia $(15 \%)$. The most common way for supplemantation was cup-feeding $(91.78 \%)$. Lower gestational-week (GW) and low-birth-weight (LBW), cesarean delivery (C/S), in-vitro fertilisation (IVF) of pregnancy, shorter breastfeeding duration of the siblings were significantly higher in formula-supplemented group. The factors associated with in-hospital formula supplementation in univariant analysis were assessed with Logistic regression; LBW, C/S delivery, and IVF pregnancy were still significant in formula-supplemented group.

Conclusion: Our results identified several factors that enhance supplementation in hospital. Healthcare professional recommendations and support before and after delivery may reduce the adverse effects of lower GW and birth weight and IVF pregnancy. Special care is needed for mothers delivering by C/S to enable to initiate and maintain breastfeeding.
\end{abstract}

Selma Aktaş, Dr. Öğr. Üye. Acıbadem Mehmet Ali Aydınlar Üniversitesi, Tıp Fakültesi, Çocuk Sağlığı ve Hastalıkları Anabilim Dalı, iSTANBUL, e-posta: selmaktas@gmail.com (orcid.org/0000-0001-7858-7292) (Sorumlu Yazar)

Ebru Kazancı, Dr. Öğr. Üye. Acıbadem Mehmet Ali Aydınlar Üniversitesi, Tıp Fakültesi, Çocuk Sağlığı ve Hastalıkları Anabilim Dalı, ISTANBUL, e-posta:ebrukazanci@yahoo.com (orcid.org/0000-0002-7920-852X)

Ayşe Korkmaz, Prof. Dr. Acıbadem Mehmet Ali Aydınlar Üniversitesi, Tıp Fakültesi, Çocuk Sağlığı ve Hastalıkları Anabilim Dalı, ISTANBUL, e-posta: korkmaz.ayse@gmail.com (orcid.org/0000-0003-4934-1124)

Zeliha Özge Kuroğlu, Hemşire, Acıbadem Maslak Hastanesi, ISTANBUL, e-posta: zeliha.ozgunes@acibadem.com (orcid.org/0000-0001-76992921 
Key words: Breastfeeding, human-milk, in-hospital formula supplementation, infant formula.

Aktaş S, Kazancı E, Korkmaz A, Kuroğlu Z.Ö. Determinant factors in formula supplementation following delivery in a baby-friendly hospital. Pam Med J 2020;13:81-90.

\section{Giriş}

Dünya Sağlık Örgütü (DSÖ), Amerikan Pediatri Akademisi (AAP) ve Birleşmiş Milletler Çocuklara Yardım Fonu (UNICEF) hayatın ilk 6 ayında sadece anne sütü ile beslenmeyi önerirken, AAP anne sütünün bir yaşına, DSÖ iki yaşına kadar sürdürülmesini önermektedir $[1,2]$. Anne sütünün büyümekte olan bir bebek için mükemmel bir besin kaynağı olmasının dışında, anneler ve çocukları için birçok hastalık riskini azalttığı bilinmektedir. Anne sütünün bebeği gastrointestinal sistem, solunum sistemi ve genel olarak bütün enfeksiyonlara karşı korumasının yanısıra [3, 4]; uzun dönemde çocuklarda obezite ve tip 2 diyabet riskini azalttığı, annelerde meme, over kanseri, tip 2 diyabet ve kardiyovaskuler hastalık riskini azalttığı bilinmektedir. Ayrıca annede daha az doğum sonrası kanama ve daha hızlı kilo kaybı ile ilişkilidir [4]. Emzirmenin yararları doza bağımlıdır, birkaç hafta daha fazla emzirmek bile hem anne hem de bebek için daha fazla yarar sağlayacaktır [5]. Hastanelerde yenidoğan bebeğin bakımını iyileştirmek için pek çok uygulama geliştirilmektedir. Bunlar arasında en yaygın kullanılanı Bebek Dostu Hastane İnisiyatifi'nden bir grup uzman tarafından geliştirilen başarılı emzirme için 10 adım politikasıdır. Bu 10 adımdan 4. adım doğumdan sonraki ilk 1 saat içinde bebeklerin anneleri ile ten teması kurmasını ve emzirmenin başlatılmasını sağlamak, 6. adım tıbben gerekli görülmedikçe yenidoğanlara anne sütünden başka yiyecek vermemek ve 9 . adım emzirilen bebeklere emzik vermemektir [6]. Yapılan çalışmalar yenidoğanlara erken başlanan formül sütün, formül süt kullanımının devamlılığına ve emzirmenin erken kesilmesine katkısı olduğunu göstermektedir [7]. Sağlıkı yenidoğanların büyük bir çoğunluğu doğumdan sonra hastanede takipleri sırasında formül süt ile desteklenmektedir ve bu oran $\% 23$ ile $\% 82$ arasında değişmektedir [8]. Bir çalışmada doğumdan sonra hastanede formül süt desteği alan bebeklerde hayatın 30 ile 60 . günleri arasında sadece anne sütü ile beslenme oranı iki kat daha düşük, 60. günde emzirmenin sonlandırılması yaklaşık üç kat daha yüksek bulunmuştur [9].

Yenidoğanın özellikle hastane takibi sırasında formül süt ile desteklenmesi, anne ve yenidoğan sağlığını, laktasyonun düzenlenmesini ve emzirme süresini etkileyebilir. Hastanede formül süt desteğinden kaçınmanın emzirmenin başarısında kilit nokta olduğu düşünülmektedir. $\mathrm{Bu}$ nedenle bu çalışmada bebek dostu olan hastanemizde doğumdan sonra eve taburculuğa kadar geçen sürede yenidoğanların formül süt ile desteklenme oranını saptamayı, formül süt verilme nedenlerini ve formül süt verilmesini etkileyen faktörleri araştırmayı hedefledik.

\section{Gereç ve yöntem}

Çalışma İstanbul'da bebek dostu sertifikası olan özel bir hastanede Ocak-Aralık 2018 tarihleri arasında doğan, anne yanında izlenen, sağlıklı yenidoğanlar ve annelerinin dosyaları ve kayıtlı verileri geriye dönük taranarak yapıldı. Çalışmaya 503 anne-bebek çifti dahil edildi. Herhangi bir nedenle yenidoğan yoğun bakım ünitesine yatırılan bebekler çalışma dışı bırakıldı. Hastanemizin DSÖ ve UNICEF'in ortak bildirisi olan Başarılı Emzirmede 10 Adım stratejileri temel alınarak oluşturulan yazılı bir emzirme politikası vardır. Bebek odasında çalışan ve yenidoğanlar ile ilgilenen her sağlık personeli bu politikayı bilir ve belli aralıklarla bu konuda eğitimler tekrarlanır. Doğumdan önce ve sonra her anne emzirme konusunda bilgilendirilir ve bebeğini emzirmesine yardımcı olunur. Taburculuğa kadar anne-bebek çiftine emzirme konusunda yardımcı olan ve emzirme başarısını takip eden ve destekleyen bir hemşire olduğu gibi taburculuktan önce ve sonra emzirme konusunda hem telefonla hem de poliklinikte anneye danışmanlık veren bir emzirme danışmanımız mevcuttur. Bebek Dostu Hastane sertifikası olan hastanemizde doğumdan sonra hastanede takip sırasında formül süt desteği alan yenidoğanların oranı, formül süt ile desteklenme nedenleri ve bunu etkileyen faktörleri araştırdığımız çalışmada 
annenin yaşı, paritesi, multipar ise diğer çocuklarını emzirme süresi, gebeliğe ait özel durumlar ile sigara alışkanlığı ve çalışma durumu sorgulandı. Yenidoğan bebeklere yönelik ise gebelik yaşı, doğum şekli, cinsiyeti, doğum ağırlığı, boyu, göğüs çevresi ve baş çevresi, 1. ve 5. dakika Apgar skoru, doğumdan sonra hastanede kalış süresi, hastane takibi sırasında \% olarak tartı kaybı, emzirme durumu, hastanede takip sırasında formül süt desteği alıp almadığı, aldı ise ne ile verildiği ve hastane takibi sırasında emzik kullanımı sorgulandı. Bebeklere formül süt verme tıbbi endikasyonları anne sütü yetersizliği ve hipoglisemi olarak belirlendi. Anne sütü yetersizliğine anne-bebek çiftini değerlendiren hemşire gözlemi yanısıra günlük tartı kaybı değerlendirilerek (günlük tartı kaybının >\%3 üzerinde olması) karar verildi. Kan şekeri izlemi bütün bebeklere yapılmadı; riskli bebeklerin (Gestasyon yaşına göre küçük ve büyük bebekler, diyabetik anne bebekleri) hepsine doğumu takiben 1 . ve 4 . saatte, bebeğin yeterince beslenmediği ya da hipoaktif olduğu düşünülen durumlarda hekim kararı ile kan şekeri izlemi yapıldı. Kan şekerinin 47 mg/ dl ve altında olması hipoglisemi olarak kabul edildi.

Çalışma için üniversitemiz etik kurulundan 09.05.2019 tarih ve 2019-9/2 karar numarası ile etik kurul onayı alınmıştır.

\section{İstatistik}

$\mathrm{Bu}$ çalışmada istatistiksel analizler NCSS (Number Cruncher Statistical System) 2007 Statistical Software (Utah, USA) paket programı ile yapılmıştır. Verilerin değerlendirilmesinde tanımlayıcı istatistiksel metotların (ortalama, standart sapma)yanı sıra Shapiro-Wilk normallik testi ile değişkenlerin dağılımı değerlendirilmiş; normal dağılım gösteren değişkenler için ikili grupların karşılaştırmasında bağımsız $t$ testi, normal dağılım göstermeyen değişkenler için ikili grupların karşılaştırmasında Mann-Whitney $U$ testi, nitel verilerin karşılaştırmalarında kikare testi kullanılmıştır. Çocukların formül süt kullanımını etkileyen faktörleri belirlemek için Logistik Regresyon analizi yapılmıştır. Sonuçlar, anlamlılık $p<0,05$ düzeyinde değerlendirilmiştir.

\section{Bulgular}

Çalışmaya 503 anne-bebek çifti dahil edildi. Yenidoğanların \%52,49'u (n:265) erkek olup;

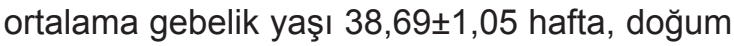

ağırlığı $3333,14 \pm 407,7 \mathrm{gr}$, boy $49,95 \pm 1,54 \mathrm{~cm}$, baş çevresi $34,59 \pm 1,17 \mathrm{~cm}$, göğüs çevresi $33,3 \pm 1,17 \mathrm{~cm}$ idi (Tablo 1). Birinci ve 5.dakika Apgar skor ortalaması sırasıyla $8,73 \pm 0,63$ ve $9,78 \pm 0,46$ idi. Yenidoğanların \%66,8'i (n:336) C/S ile doğdu. C/S doğumların \%96'sında epidural anestezi uygulandı. Gebeliklerin \%10,14'ü (n:51) in vitro fertilizasyon (IVF) gebelikti. Gebeliklerin \%33'ü (n:166) multipardı. Annelerin yaş ortalaması 32,92ะ4,29 idi. IVF gebeliği olan annelerin medyan yaşı 35 (min: 27, max: 45) olup; IVF gebelerin yaşları gebeliği spontan olanlara göre yüksekti. Annelerin \%12,33'ünde ( $\mathrm{n}: 62)$ gestasyonel diyabetes mellitus (GDM) olup; bunların sadece üçü insülin ile regüle, geri kalanı diyetle regüle idi. Annelerin \%8,95'inde (n:45) hipotiroidiye bağlı levotiroksin kullanma öyküsü vardı. Annelerin \%81,11'i (n:408) çalışıyordu. Annelerin \%3,98'i (n:20) gebelik sırasında sigara kullandığını ve \%3,38'i de (n:17) gebelik sırasında bıraktığını bildirdi. Hastanede yatışları sırasında yenidoğanların \%88,07'sinin memeyi aktif emdiği, \%6,36'sının silikonla aktif emdiği, \%5,17'sinin hemşire yardımı ile emdiği, \%0,4'nün pasif olduğu tespit edildi. Bu yenidoğanların \%14,5’i (n:73) doğumdan sonraki hastane takipleri sırasında formül süt ile desteklendi. Formül süt ile desteklenenlerin $\% 78,08$ 'inde neden anne sütü yetersizliği, $\% 15,07$ 'sinde hipoglisemi ve \%6,85'inde aile isteğiydi. Formül süt vakaların \%91,78'ine (n:67) fincan, \%2,74'üne (n:2) biberon ve \%5,48'ine $(n: 4)$ bebek anne memesini emerken beslenme sondası kullanılarak verildi. Hastanemiz emzirme politikası gereğince yenidoğanlara doğumdan sonra hastane takipleri sırasında biberon ve emzik önerilmemektedir. Çalışmaya katılan iki vakada aile isteği nedeniyle emzik ve biberon kullanıldı (Tablo 2). Anne ya da bebeğin daha uzun yatışını gerektirecek bir durum yoksa hastanemizde normal spontan vajinal yol ile doğan yenidoğanlar 24. saatte, C/S ile doğanlar 48. saatte taburcu olurlar. Yirmidört, 48 ve 72 . saatte taburcu olanların doğum ağırlığına göre ortalama \% olarak ağırık kayıpları sırasıyla $3,86 \pm 1.8,7,16 \pm 1,66$ ve $6,73 \pm 2,11$ idi. Sadece anne sütü ile beslenen yenidoğanlar ile formül süt desteği alanlar karşılaştırıldığında gebelik yaşı ve doğum ağırlığı formül süt desteği alan grupta anlamlı düşüktü. Formül süt alan grupta $\mathrm{C} / \mathrm{S}$ ile doğum anlamlı daha yüksek, doğumdan sonra hastanede kalış süresi anlamlı daha uzundu. Paritenin ve kardeş sayısının formül süt desteği alımı ile ilişkisi gösterilemezken, 
daha önceki kardeş ya da kardeşlerin emzirilme süresi formül süt desteği alan grupta daha kısaydı. IVF gebeliklerde formül süt desteği alan yenidoğanların sayısı anlamlı daha yüksekti. Formül süt desteği alan grupta aktif emmenin istatistiksel olarak anlamlı düşük, silikonla aktif ve hemşire yardımıyla aktif emmenin daha yüksek olduğu bulunmuştur. Sadece anne sütü ile beslenen grup ile formül süt desteği alan grup karşılaştıııldığında 1, 2 ve 3 . gün \% ağırlık kaybı, annenin sigara kullanımı ve annenin çalışma durumu açısından anlamlı bir fark tespit edilmedi. Formül süt desteği verilen grupta formül süt kullanımını etkilediği düşünülen faktörler Tablo 3'de gösterildi. Yenidoğanların doğumdan sonra hastane takipleri sırasında formül süt kullanımını etkileyen faktörleri belirlemek için yapılan univariet analizlerde anlamlı bulunan gebelik yaşı, doğum ağırlığı, doğumdan sonra hastanede kalış süresi, IVF gebelik ve doğum şekli değişkenleri ile logistik regresyon analizi yapıldığında doğum ağırlığı, doğum şekli ve IVF gebelik durumunun anlamlılığını sürdürdüğü görüldü (Tablo 4).

\section{Tartışma}

Bebek dostu olan hastanemizde doğum sonrası hastane takibi sırasında formül süt desteği verilme nedenlerini ve formül süt destek gereksinimini arttıran risk faktörlerini araştırdığımız çalışmamızda; en sık nedenin anne sütü yetersizliği olduğu tespit edilirken; univariet analizlerde risk faktörü olarak tespit edilen düşük gebelik yaşı ve düşük doğum ağırlığı, C/S doğum ve IVF gebelik değişkenleri ile yapılan logistik resresyon analizinde düşük doğum ağırlığı, C/S doğum ve IVF gebeliğin anlamlııı̆ını sürdürdüğü görüldü.

Emzirmeye başlama oranları dünya genelinde oldukça farklıdır; bu oran Norveç, Danimarka ve Japonya'da yaklaşık \%99, Almanya'da \%90 ve ABD'de \%74,6'dır [10]. Türkiye Nüfus Sağlığı Araştırması (TNSA) 2013 verilerine göre Türkiye'de bu oranın sağlık çalışanlarının yardımıyla \%70'lerde olduğu bildirilmektedir [11]. Bizim çalışmamızda doğumdan sonra her yenidoğan mümkün olan en kısa sürede emzirilmeye başlandı, hastaneden taburcu olurken bu bebeklerin $\% 85,5$ 'i sadece anne sütü ile beslenirken $\% 14,5$ 'i anne sütü ile birlikte formül süt desteği almaktaydı. Bu oranları etkileyebileceği düşünülen risk faktörleri bugüne kadar farklı çalışmalarda araştırılmıştır. Bu risk faktörlerinden birinin doğum şekli olduğu düşünülmektedir. New York'ta normal spontan vajinal yol (NSVY) ile doğan bebeklerin \%46,4'ü hastane takipleri sırasında formül süt desteği alırken, C/S ile doğanlarda bu oran \%53,6 idi [12]. Chen ve ark.'nın [13] çalışmasında C/S ile doğum yapan kadınlarda hastane takipleri sırasında formül süt kullanma oranının NSVY ile doğum yapanlara göre 3.5 kat daha yüksek

Tablo 1. Çalışmaya katılan bebeklerin demografik özellikleri.

\begin{tabular}{lllll}
\hline & OrtıSS & Median (IQR) & Minimum & Maximum \\
\hline Gebelik Yaşı (hafta) & $38,69 \pm 1,05$ & $38,6(38,1-39,4)$ & 35,3 & 41,2 \\
Vücut Ağırığı (gr) & $3333,14 \pm 407,7$ & $3330(3085-3610)$ & 2080 & 4535 \\
Boy (cm) & $49,95 \pm 1,54$ & $50(49-51)$ & 42 & 53 \\
Baş Çevresi (cm) & $34,59 \pm 1,17$ & $35(34-35)$ & 31 & 37 \\
Göğüs Çevresi (cm) & $33,3 \pm 1,42$ & $33(32,5-34)$ & 28 & 37 \\
Hastanede Kalış Süresi (gün) & $1,76 \pm 0,61$ & $2(1-2)$ & 1 & 3 \\
Tartı Kaybı (\%) & $6,09 \pm 2,31$ & $6,3(4,5-8)$ & 0 & 11 \\
Anne Yaşı (yıl) & $32,92 \pm 4,29$ & $33(30-36)$ & 21 & 48 \\
Yaşayan Kardeş Sayısı & $1,22 \pm 0,59$ & $1(1-1)$ & 1 & 6 \\
Emzirme Süresi (ay) & $13,67 \pm 7,55$ & $14,5(7-18)$ & 1 & 36 \\
Tartı Kaybı (\%) 1.Gün & $3,86 \pm 1,8$ & $4(2,5-5)$ & 0 & 9 \\
Tartı Kaybı (\%) 2.Gün & $7,16 \pm 1,66$ & $7,4(6-8,35)$ & 1 & 11 \\
Tartı Kaybı (\%) 3.Gün & $6,73 \pm 2,11$ & $7(5,38-8,63)$ & 3 & 9,5 \\
\hline
\end{tabular}


Tablo 2. Çalışmaya katılan anne ve bebeklerin özellikleri.

\begin{tabular}{|c|c|c|c|}
\hline \multirow{3}{*}{ Cinsiyet } & \multirow[b]{2}{*}{ Kız } & \multicolumn{2}{|c|}{ Tüm Grup \% } \\
\hline & & 238 & 47,32 \\
\hline & Erkek & 265 & 52,68 \\
\hline \multirow{4}{*}{ Doğum Şekli } & C/S Epidural & 324 & 64,41 \\
\hline & C/S Spinal & 2 & 0,40 \\
\hline & C/S Genel & 10 & 1,99 \\
\hline & Normal Spontan Doğum & 167 & 33,20 \\
\hline \multirow{3}{*}{ Anne Çalışıyor mu? } & Hayır & 95 & 18,89 \\
\hline & Evet & 408 & 81,11 \\
\hline & Hayır & 466 & 92,64 \\
\hline \multirow[t]{2}{*}{ Sigara Kullanımı } & Evet & 20 & 3,98 \\
\hline & Gebelikte Bırakmış & 17 & 3,38 \\
\hline \multirow{2}{*}{ Annede Diyetle Regüle GDM } & Yok & 444 & 88,27 \\
\hline & Var & 59 & 11,73 \\
\hline \multirow{2}{*}{ Annede İnsülin ile Regüle GDM } & Yok & 500 & 99,40 \\
\hline & Var & 3 & 0,60 \\
\hline \multirow{2}{*}{ Annede Hipotiroidi } & Yok & 458 & 91,05 \\
\hline & Var & 45 & 8,95 \\
\hline \multirow{2}{*}{ IVF Gebelik } & Yok & 452 & 89,86 \\
\hline & Var & 51 & 10,14 \\
\hline \multirow{4}{*}{ Emzirme Durumu } & Aktif & 443 & 88,07 \\
\hline & Silikonla Aktif & 32 & 6,36 \\
\hline & Aktif Yardımlı & 26 & 5,17 \\
\hline & Pasif & 2 & 0,40 \\
\hline \multirow{3}{*}{ FS Destek Nedeni } & Anne Sütü Yetersizliği & 57 & 78,08 \\
\hline & Hipoglisemi & 11 & 15,07 \\
\hline & Aile İsteği & 5 & 6,85 \\
\hline \multirow{3}{*}{ FS Verilme Yolu } & Fincan ile & 67 & 91,78 \\
\hline & Biberon & 2 & 2,74 \\
\hline & Beslenme Sondası & 4 & 5,48 \\
\hline \multirow{2}{*}{ Emzik Kullanımı } & Yok & 501 & 99,60 \\
\hline & Var & 2 & 0,40 \\
\hline \multirow{2}{*}{ Biberon Kullanımı } & Yok & 501 & 99,60 \\
\hline & Var & 2 & 0,40 \\
\hline
\end{tabular}

C/S: sezaryen doğum, GDM: gestasyonel diyabetes mellitus, IV:F in vitro fertilizasyon, FS: formül süt 
Tablo 3. Hastanede formül-süt desteği alan ve sadece anne sütü ile beslenen bebeklerin özelliklerinin karşılaştıııması.

\begin{tabular}{|c|c|c|c|c|c|c|}
\hline & & \multicolumn{2}{|c|}{$\begin{array}{l}\text { Anne Sütü Grubu } \\
\mathrm{n}: 430\end{array}$} & \multicolumn{2}{|c|}{$\begin{array}{c}\text { Anne Sütü+ } \\
\text { Mama Grubu n:73 }\end{array}$} & $p$ \\
\hline \multicolumn{2}{|l|}{ Gebelik yaşı (hafta) (ort $\pm S S$ ) } & \multicolumn{2}{|c|}{$38,79 \pm 0,98$} & \multicolumn{2}{|c|}{$38,10 \pm 1,23$} & $0,0001^{*}$ \\
\hline \multirow{2}{*}{ Cinsiyet (n, \%) } & Kız & 200 & 46,51 & 38 & 52,05 & \multirow{2}{*}{0,381} \\
\hline & Erkek & 230 & 53,49 & 35 & 47,95 & \\
\hline \multirow{2}{*}{ Doğum Şekli (n, \%) } & NSD & 157 & 36,51 & 10 & 13,70 & \multirow{2}{*}{$0,0001+$} \\
\hline & C/S Doğum & 273 & 63,49 & 63 & 86,30 & \\
\hline \multicolumn{2}{|l|}{ Vücut Ağırlığı (gram) (ortıSS) } & \multicolumn{2}{|c|}{$3362,95 \pm 372,98$} & \multicolumn{2}{|c|}{$3157,53 \pm 541,7$} & $0,0001^{*}$ \\
\hline \multicolumn{2}{|c|}{ Hastanede Kalış Süresi (gün) (ortıSS) } & \multicolumn{2}{|c|}{$1,69 \pm 0,56$} & \multicolumn{2}{|c|}{$2,18 \pm 0,69$} & $0,0001 \ddagger$ \\
\hline \multicolumn{2}{|c|}{ Anne Yaşı (yıl) (ortıSS) } & \multicolumn{2}{|c|}{$32,87 \pm 4,32$} & \multicolumn{2}{|c|}{$33,21 \pm 4,12$} & $0,540^{*}$ \\
\hline \multirow[t]{2}{*}{ Anne Çalışıyor mu? (n, \%) } & Hayır & 80 & 18,60 & 15 & 20,55 & \multirow{2}{*}{$0,695+$} \\
\hline & Evet & 350 & 81,40 & 58 & 79,45 & \\
\hline \multirow[t]{2}{*}{ Parite (n, \%) } & Primipar & 290 & 67,44 & 47 & 64,38 & \multirow{2}{*}{0,607} \\
\hline & Multipar & 140 & 32,56 & 26 & 35,62 & \\
\hline \multicolumn{2}{|c|}{ Yaşayan Kardeş Sayısı (ort_SS) } & \multicolumn{2}{|c|}{$1,21 \pm 0,47$} & \multicolumn{2}{|c|}{$1,31 \pm 1,01$} & $0,795 \ddagger$ \\
\hline \multirow{2}{*}{\multicolumn{2}{|c|}{$\begin{array}{l}\text { Emzirme Süresi (ay) (ortıSS) } \\
\text { Sigara Kullanımı (n, \%) }\end{array}$}} & \multicolumn{2}{|c|}{$14,12 \pm 7,52$} & 10,8 & & $0,033 \ddagger$ \\
\hline & Hayır & 398 & 92,56 & 68 & 93,15 & \\
\hline & Evet & 17 & 3,95 & 3 & 4,11 & $0,947+$ \\
\hline & Gebelikte Bırakmış & 15 & 3,49 & 2 & 2,74 & \\
\hline Annede Diyetle Regüle & Yok & 381 & 88,60 & 63 & 86,30 & $0572+$ \\
\hline GDM (n, \%) & Var & 49 & 11,40 & 10 & 13,70 & $0,512^{+}$ \\
\hline Annede İnsülin ile Regüle & Yok & 429 & 99,77 & 71 & 97,26 & $t$ \\
\hline GDM (n, \%) & Var & 1 & 0,23 & 2 & 2,74 & $0,01+$ \\
\hline Annede Hipotiroidi (n, \%) & Yok & 390 & 90,70 & 68 & 93,15 & \\
\hline & Var & 40 & 9,30 & 5 & 6,85 & $0,491+$ \\
\hline IVF Gebelik (n, \%) & Yok & 403 & 93,72 & 49 & 67,12 & $00001+$ \\
\hline & Var & 27 & 6,28 & 24 & 32,88 & 0,000 IT \\
\hline Emzirme Durumu (n, \%) & Aktif & 391 & 90,93 & 52 & 71,23 & \\
\hline & Silikonla Aktif & 22 & 5,12 & 10 & 13,70 & \\
\hline & Aktif Yardımlı & 16 & 3,72 & 10 & 13,70 & $0,0001+$ \\
\hline & Pasif & 1 & 0,23 & 1 & 1,37 & \\
\hline Emzik Kullanımı (n, \%) & Yok & 430 & 100,00 & 71 & 97,26 & + \\
\hline & Var & 0 & 0,00 & 2 & 2,74 & \\
\hline Biberon Kullanımı (n, \%) & Yok & 430 & 100,00 & 71 & 97,26 & $001+$ \\
\hline & Var & 0 & 0,00 & 2 & 2,74 & $0,001+$ \\
\hline Tartı Kaybı (\%) 1.Gün (ortt & & $3,81 \pm$ & & & 1,68 & $0,106 \ddagger$ \\
\hline Tartı Kaybı (\%) 2.Gün (ort土 & & $7,12 \pm$ & & & 1,33 & $0,488 \ddagger$ \\
\hline Tartı Kaybı (\%) 3.Gün (ort土 & & $6,64 \pm$ & & & 01 & $0,117 \ddagger$ \\
\hline
\end{tabular}

*Bağımsız $\mathrm{t}$ testi $¥$ Mann Whitney $\mathrm{U}$ testi +Ki kare testi NSD: normal spontan doğum, C/S: sezaryen doğum, GDM: gestasyonel diyabetes mellitus, IVF: in vitro fertilizasyon, FS: formül süt 
Tablo 4. Hastanede formül süt desteği gereksinimini arttıran faktörler.

\begin{tabular}{llccccc}
\hline & B & S.E. & $\boldsymbol{p}$ & OR & \multicolumn{3}{c}{ OR \%95 } \\
& & & & & & \\
& $-0,51$ & 0,28 & 0,065 & 1,67 & 0,97 & 2,86 \\
\hline Gebelik Yaşı & $-0,58$ & 0,27 & $\mathbf{0 , 0 2 8}$ & 0,56 & 0,33 & 0,94 \\
Vücut Ağırlığı & 0,13 & 0,90 & 0,883 & 1,14 & 0,20 & 6,62 \\
Hastanede Kalış Süresi & 2,07 & 0,58 & $\mathbf{0 , 0 0 0 1}$ & 0,13 & 0,04 & 0,39 \\
IVF Gebelik Varlığı & 2,30 & 0,84 & $\mathbf{0 , 0 0 6}$ & 0,10 & 0,02 & 0,52 \\
Doğum Şekli C/S & & & & & & \\
\hline
\end{tabular}

IVF: in vitro fertilizasyon, C/S: sezaryen doğum

olduğu ve emzirmeye başlamanın gecikmesinin 6.5 kat daha fazla olduğu tespit edilmiştir. Bizim çalışmamızda da benzer olarak formül süt desteği alanların \%13,7'si NSVY ve \%86,3'ü ise $\mathrm{C} / \mathrm{S}$ ile doğanlardır. $\mathrm{C} / \mathrm{S}$ doğum emzirmenin başlatılmasını geciktirmektedir, bunun olası nedenleri postoperatif bakım nedeni ile postpartum anne-bebek buluşmasının gecikmesi [14] ve NSVY ile doğumlara göre annenin daha fazla ağrı duyması, cerrahi girişim sırasında uygulanan anestezi, intravenöz kateterler ve abdominal kesi nedeniyle emzirme için rahat pozisyon bulmanın zorluğudur. Ayrıca hasta bakım personelinde cerrahi müdahaleden sonra annelerin dinlenmeye intiyacı vardır algısı nedeniyle C/S ile doğan bebekler vajinal yolla doğan akranlarına göre annelerinden daha uzun süre ayrı kalıyor ve ten-tene temas gecikiyor olabilir [13]. Bu nedenle elektif C/S doğumdan kaçınılmalı, anneler elektif $\mathrm{C} / \mathrm{S}$ doğumun bebek beslenmesi üzerine olan potansiyel etkileri açısından bilgilendirilmelidir. C/S doğum yapan anneler için anne-bebek buluşması hızlandırılmalı, aile üyeleri ile anne ve bebeğe bakım veren hastane personeli emzirmenin yararları konusunda eğitilmeli, doğumdan sonra hastane takipleri sırasında anneler tıbbi endikasyon dışında formül süt kullanımından vazgeçirilmelidir. Kalmakoff ve ark.'ı [15] bizim çalışmamızın ve literatürdeki pek çok diğer çalışmaların aksine $\mathrm{C} / \mathrm{S}$ doğumu, formül süt destek gereksinimi için bir risk faktörü olarak tespit etmediklerini bildirmişlerdir. Bu durumun $\mathrm{C} / \mathrm{S}$ doğumdan sonra anne bebek arasında ten temasının doğumdan sonra mümkün olan en kısa zamanda (5-15 dakika) sağlanması ile ilişkili olabileceğini rapor etmişlerdir. Çalışmalarında yenidoğanların \%95'inde bir saat içinde ten temasının sağlandığını ve bu durumun doğum şeklinin formül süt desteği üzerine olan etkisini iyileştirmiş olabileceğini belirtmişlerdir. Parry ve ark.'nın [16] çalışmasında, formül süt desteği gereksinimini $\mathrm{C} / \mathrm{S}$ doğum, müdahaleli vajinal doğum ve doğum ağırlığının $\geq 3250 \mathrm{~g}$ olmasının arttırdığı, emzirmenin doğum odasında başlatılmasının ise azalttığını göstermişlerdir. Aynı çalışmada doğumu takiben ilk 24 saat sadece anne sütü ile beslenenlerin herhangi bir miktarda formül süt desteği alanlara göre emzirme sürelerinin daha uzun olduğu görülmüştür. Sosyodemografik değişkenler düzenlendikten sonra bile, hastanede formül süt desteği alan bebeklerin, hastaneden sadece anne sütü ile beslenerek ayrılanlara göre sütten kesilme olasılııkları daha yüksek bulunmuştur.

Boban ve ark.'ının [17] çalışmasında doğumdan sonra hastane takipleri boyunca yenidoğanların \%62,8'inin formül süt ile desteklendiği tespit edilmiştir. Aynı çalışmada annelerin \%97'sinin fincan kullanırken geriye kalan çok azının biberon kullandığı görülmüş ve annelerin formül süt desteği vermelerinin en sık nedenleri anne sütü eksikliği $(\% 49,8)$, bebeğin ağlaması $(\% 35,5), \mathrm{C} / \mathrm{S}$ doğumu takiben güçsüzlük/ağrı $(\% 11,5)$, tartı kaybı $(\% 10,6)$ ve ağrılı meme başı $(\% 10,1)$ olarak bildirilmiştir. Chantry ve ark.'nın çalışmasında [9] ilk kez anne olan ve bebeklerini sadece anne sütü ile besleme niyetinde olan kadınların hastane takipleri sırasında formül süt desteği verme oranının $\% 47$ olduğu, formül süt desteği verilmesinde annelerin öne sürdüğü en yaygın nedenlerin ise anne sütü yetersizliği ve bebeklerin emme yetersizliği olduğu belirtilmiştir. Aynı çalışmada, hastane takibi sırasında formül süt desteği diğer alternatif yöntemler yerine biberon ile verildiğinde, yaşamın 30 ile 60 günleri arasında sadece anne sütü ile beslenme oranının anlamlı düşük olduğu saptanmıştır. Benzer şekilde Howard ve ark'ına [18] göre hastane takipleri sırasında formül süt desteğini biberon yerine 
fincan ile alan bebeklerin sadece anne sütü ile beslenme süreleri daha uzun bulunmuştur. Çalışmamızda doğumdan sonra hastane takipleri boyunca formül süt desteği alma oranı çok daha düşük idi $(\% 14,5)$ ve formül süt desteği DSÖ ve UNICEF önerilerine uygun olarak çok büyük oranda $(\% 91,78)$ fincan ile verildi. Benzer olarak formül süt desteği verilmesinin en sık nedeni anne sütü yetersizliği $(\% 78,08)$, diğer nedenler ise hipoglisemi $(\% 15,07)$ ve ailenin formül süt desteği verilmesini istemesi idi $(\% 6,85)$. Aktif emen bebeklerde, silikonla aktif ya da hemşire desteği ile aktif emenlere göre formül süt desteği intiyacı anlamlı düşük bulundu $(p=0,0001)$.

Tıp Emzirme Akademisi (ABM), laktogenezisin 2. evresindeki gecikmenin ve yenidoğanın doğum ağırığının \%8-10 tartı kaybının eşlik ettiği durumlarda formül süt desteği önermektedir. Çalışmamızda 24, 48 ve 72. saatte taburcu olanların doğum ağırlığına göre ortalama ağırlık kaybı yüzde olarak sırasıyla $3,86 \pm 1,8 ; 7,16 \pm 1,66$ ve $6,73 \pm 2,11$ idi. Sadece anne sütü ile beslenenler ile formül süt desteği alanlar arasında \% ağırlık kaybı açısından istatiksel anlamlı fark olmamakla birlikte, formül süt desteği alan grupta \% ağırlık kaybının daha yüksek olduğu izlendi. Bu da aslında formül süt desteğinin büyük çoğunlukla tıbbi olarak gereksinimi olan bebeklere verildiğinin, iyi bir danışmanlık ve destek verilirse formül süt desteği gereksiniminin belirgin azalacağının bir göstergesidir.

Literatürde bir çalışmada maternal obezite, primipar doğum, gebelik yaşının 40 haftadan ve doğum ağırlığının 2500 gramdan düşük olması formül süt desteği için bağımsız risk faktörü olarak gösterilmektedir [15]. Gebelik yaşının 37-39 hafta olması, emzirmeye başlama oranlarının yüksek olduğu ülkelerde dahi emzirme başarısızlığı için risk faktörü olarak rapor edilmektedir $[19,20]$. Bu durumun doğum indüksiyonu uygulanan veya 39 haftadan önce elektif C/S uygulanan gebeler için klinik önemi vardır. Çalışmamızda da benzer olarak formül süt desteği alan grupta doğum ağırlığı ve gebelik yaşı anlamlı olarak düşük tespit edildi. Bu nedenle doğum kararını verirken bu durumun emzirme üzerine olabilecek potansiyel etkisi anneler ile paylaşılmalıdır.
Pek çok çalışma ilk kez anne olanların multipar annelere göre daha fazla formül süt desteği kullandığını göstermektedir [4, 21]. Declercq ve ark.'ı [4], "Başarılı Emzirmede 10 Adım” stratejilerinden 6-7'sinin yerine getirilmesi halinde, multipar ve primipar annelerin bebekleri arasında sadece anne sütü ile besleme hedefi açısından anlamlı bir fark olmadığını bildirmektedirler. Giderek artan bir oranda gösterilmektedir ki, daha önceki emzirme tecrübesi daha sonraki emzirme davranışında pariteden daha önemli bir rol oynamaktadır. Taylor ve ark.'ı [22] ilk çocuklarını emziren multipar annelerin pariteden bağımsız olarak daha sonra doğan çocuğunu büyük bir olasılıkla emzirdiğini bildirmektedirler. Amerika Birleşik Devletleri'nden bir çalışmada, hiç emzirme deneyimi olmayan anneler ile ilk çocuklarını <4 ay veya $\geq 4$ ay sadece anne sütü ile besleyen anneler karşılaştırıldığında; 2 . gruptaki annelerin ikinci çocuklarını $\geq 4$ ay sadece anne sütü ile besleme oranlarının daha yüksek olduğu bulunmuştur [23]. Bizim çalışmamızda parite ve kardeş sayısının formül süt desteği gereksinimi ile ilişkisi gösterilemezken, daha önceki kardeş ya da kardeşlerin emzirilme süresinin sadece anne sütü ile beslenen grupta anlamlı daha uzun olduğu gösterildi. Geçmiş emzirme deneyiminin daha uzun olması daha sonraki çocukta annenin özgüvenini ve yeterliliğini arttırarak emzirme devamlılığını pozitif yönde etkilemiş olabilir. $\mathrm{Bu}$ nedenle ilk defa anne olanların daha uzun süre emzirmeleri konusunda desteklenmesi sadece mevcut çocuk yararına olmakla kalmaz, aynı zamanda bir sonraki çocuktaki emzirme davranışını da etkiler. Ayrıca hastanemizin emzirmeyi destekleyici uygulamaları, primiparite ile ilişkili olduğu düşünülen formül süt desteği gereksinimi artışının ortadan kalkmasına yardımcı olmuş olabilir.

Yardımcı üreme teknikleri (YÜT) ile doğan yenidoğanlar, C/S doğum, prematüre doğum, düşük doğum ağırlığı ve perinatal mortalite gibi obstetrik komplikasyonlara ve perinatal olumsuz sonuçlara daha fazla maruz kalmaktadırlar [24]. Fisher ve ark.'ı [25] YÜT ile gebe kalan kadınlarda anksiyete ve emzirme zorlukları gibi erken dönem ebeveynlik problemlerinin daha fazla olduğunu göstermişlerdir. Monti ve ark.'। [10, 26] YÜT ile gebe kalan kadınlarda daha fazla anksiyete ve emosyonel kırılganlık olduğunu, bunun depresyon riskini arttırdığını ve annebebek ilişkisi üzerine olası olumsuz sonuçlarını 
vurgulamaktadırlar. Castelli ve ark.'nın [10] IVF ile gebe kalan kadınların bebeklerini emzirme konusundaki kararlarını olumsuz etkileyen maternal faktörlerin araştııılığı çalışmalarında, buna etki eden üç faktör tespit etmişlerdir; infertilite süresinin iki yıldan daha uzun olması, C/S doğum ve annelerin kendilerinin yenidoğan döneminde formül süt ile beslenmiş olması. Aynı çalışmada annelerin doğum sırasındaki ortalama yaşı $32,7 \pm 4,5$ yıl, C/S ile doğum oranı \%42 (n:31) olarak saptanmıştır. Bizim çalışmamızda annelerin ortalama yaşı 32,92 4 ,29 iken, IVF ile gebe kalan annelerin medyan yaşı 35 (min:27, max:45) idi. Çalışmamızda IVF gebelerde $\mathrm{C} / \mathrm{S}$ ile doğum ( $\mathrm{n}: 41, \% 80)$ ve formül süt ile desteklenme oranı daha yüksekti $(p=0,0001)$. IVF gebelik sonucu doğanlarda formül süt ile desteklenme oranının daha yüksek olmasının nedenleri, annelerin çok büyük bir kısmının primipar olması ve daha önce emzirme deneyiminin olmaması ve $\mathrm{C} / \mathrm{S}$ doğum oranının yüksek olması olabilir.

Çalışmamızdaki kısıtıııklardan biri çalışmanın retrospektif olması, bir diğeri ise hastaların hastaneden taburcu olduktan sonra nasıl beslendiklerine, ne kadar süre sadece anne sütü aldıklarına dair bilgimizin olmamasıdır.

Sonuç olarak, çalışmamızda doğumdan sonra hastane takiplerinde formül süt desteği gereksinimini etkileyen başlıca risk faktörleri; düşük doğum ağırlığı, C/S ile doğum ve IVF gebelik olarak tespit edildi. Doğumdan sonra anneye hem aile bireyleri hem de sağlık personeli tarafından yeterli destek verilirse, kurumun yazılı emzirme politikalarına uyulur, doğumdan sonra hastane takipleri sırasında tıbbi endikasyon dışında formül süt desteği verilmez, hastaneden taburcu olduktan sonra gerekli durumlarda poliklinikte emzirme danışmanlığı verilmeye devam edilir ve her şeyden önce çocuk hekimi ve anneye destek veren sağlık ekibi emzirmenin önemini anlar ve anneyi emzirme konusunda motive ederse $\mathrm{C} / \mathrm{S}$ doğum, IVF gebelik ve emzirme deneyiminin olmaması ya da yetersiz olması gibi risk faktörlerinin olumsuz etkileri azaltılabilir.

Çıkar ilişkisi: Yazarlar çıkar ilişkisi
bulunmadığını beyan eder.

\section{Kaynaklar}

1. Eidelman Al. Breastfeeding and the use of human milk: an analysis of the American Academy of Pediatrics 2012 Breastfeeding Policy Statement. Breastfeed Med 2012;7:323-324. https://doi.org/10.1089/ bfm.2012.0067

2. World Health Organization and UNICEF. Global strategy for infant and young child feeding. Geneva, Switzerland: World Health Organization, 2003.

3. Duijts L, Ramadhani MK, Moll HA. Breastfeeding protects against infectious diseases during infancy in industrialized countries. A systematic review. Matern Child Nutr 2009;5:199-210. https://doi.org/10.1111/ j.1740-8709.2008.00176.x

4. Dieterich CM, Felice JP, O'Sullivan E, Rasmussen KM. Breastfeeding and health outcomes for the motherinfant dyad. Pediatr Clin North Am 2013;60:31-48. https://doi.org/10.1016/j.pcl.2012.09.010

5. Tarrant M, Kwok MK, Lam TH, Leung GM, Schooling CM. Breast-feeding and childhood hospitalizations for infections. Epidemiology 2010;21:847-854. https://doi. org/10.1097/EDE.0b013e3181f55803

6. National implementation of the baby-friendly hospital initiative, 2017. Geneva: World Health Organization; 2017. Licence: CC BY-NC-SA 3.0 IGO.

7. Patil CL, Turab A, Ambikapathi R, et al. Early interruption of exclusive breastfeeding: results from the eight-country MAL-ED study. J Health Popul Nutr 2015;34:10.

8. Tarrant M, Lok KY, Fong DY, et al. Effect of a hospital policy of not accepting free infant formula on inhospital formula supplementation rates and breastfeeding duration. Public Health Nutr 2015;18:26892699. https://doi.org/10.1017/S1368980015000117

9. Chantry CJ, Dewey KG, Peerson JM, Wagner EA, Nommsen-Rivers LA. In-hospital formula use increases early breastfeeding cessation among firsttime mothers intending to exclusively breastfeed. J Pediatr 2014;164:1339-1345. https://doi.org/10.1016/j. jpeds.2013.12.035

10. Castelli C, Perrin J, Thirion X, Comte F, Gamerre M, Courbiere B. Maternal factors influencing the decision to breastfeed newborns conceived with IVF. Breastfeed Med 2015;10:26-30. https://doi.org/10.1089/ bfm.2014.0078

11. Türkiye Nüfus ve Sağlık Araştırması. http://www.hips. hacettepe.edu.tr/TNSA_2013_ana_rapor.pdf. Erişim Tarih 03 Eylül 2015.

12. Nguyen T, Dennison BA, Fan W, Xu C, Birkhead GS. Variation in formula supplementation of breastfed newborn infants in New York hospitals. Pediatrics 2017;140:e20170142. https://doi.org/10.1542/ peds.2017-0142 
13. Chen $C$, Yan $Y$, Gao X, et al. Influences of cesarean delivery on breastfeeding practices and duration: a prospective cohort study. J Hum Lact 2018;34:526534. https://doi.org/10.1177/0890334417741434

14. Esteves TM, Daumas RP, Oliveira MI, Andrade CA, Leite IC. Factors associated to breastfeeding in the first hour of life: systematic review. Rev Saude Publica 2014;48:697-708. https: //doi.org/10.1590/S00348910.2014048005278

15. Kalmakoff S, Gray A, Baddock S. Predictors of sup plementation for breastfed babies in a baby-friendly hospital. Women Birth 2018;31:202-209. https://doi. org/10.1016/j.wombi.2017.08.131

16. Parry JE, Ip DK, Chau PY, Wu KM, Tarrant M. Predictors and consequences of in-hospital formula supplementation for healthy breastfeeding newborns. J Hum Lact 2013;29:527-536. https://doi. org/10.1177/0890334412474719

17. Boban M, Zakarija-Grković. In-hospital formula supplementation of healthy newborns: practices, reasons, and their medical justification. Breastfeed Med 2016;11:448-454. https://doi.org/10.1089/ bfm.2016.0039

18. Howard CR, Howard FM, Lanphear B, et al. Randomized clinical trial of pacifier use and bottlefeeding or cupfeeding their effect on breastfeeding. Pediatrics 2003;111:511-518. https://doi.org/10.1542/ peds.111.3.511

19. Donath SM, Amir LH. Effect of gestation on initiation and duration of breastfeeding. Arch Dis Child Fetal Neonatal Ed 2008;93:448-450. https://doi.org/10.1136/ adc. 2007.133215

20. Hackman NM, Alligood-Peroco N, Martin A, Zhu J, Kjerulff $\mathrm{K}$. Reduced breastfeeding rates in firstborn late preterm and early term infants. Breastfeed Med 2016;11:119-125. https://doi.org/10.1089/ bfm.2015.0122

21. Biro MA, Sutherland GA, Yelland JS, Hardy P, Brown SJ. In-hospital formula supplementation of breastfed babies: a population-based survey. Birth 2011;38:302310. https://doi.org/10.1111/j.1523-536X.2011.00485.x

22. Taylor JS, Geller L, Risica PM, Kirtania U, Cabral HJ. Birth order and breastfeeding initiation: results of a national survey. Breastfeed Med 2008;3:20-27. https:// doi.org/10.1089/bfm.2007.0006

23. Phillips G, Brett K, Mendola P. Previous breastfeeding practices and duration of exclusive breastfeeding in the United States. Matern Child Health J 2011;15:12101216. https://doi.org/10.1007/s10995-010-0694-4

24. Allen VM, Wilson RD, Cheung A. Pregnancy outcomes after assisted reproductive technology. J Obstet Gynaecol Can 2006;28:220-233. https://doi. org/10.1016/S1701-2163(16)32112-0
25. Fisher JR, Rowe H, Hammarberg K. Admissions for early parenting difficulties among women with infants conceived by assisted reproductive technologies: a prospective cohort study. Fertil Steril 2012;97:14101416. https://doi.org/10.1016/j.fertnstert.2012.02.050

26. Monti $F$, Agostini $F$, Fagandini $P$, Paterlini $M$, La Sala GB, Blickstein I. Anxiety symptoms during late pregnancy and early parenthood following assisted reproductive technology. J Perinat Med 2008;36:425432. https://doi.org/10.1515/JPM.2008.074

$\mathrm{Bu}$ çalışma 1. Uluslararası 'Emzirme Gerçeği' Kongresi, 30 Eylül-03 Ekim 2019, The Ankara Hotel, Ankara'da sözlü bildiri olarak sunulmuştur.

Çalışma, Acıbadem Mehmet Ali Aydınlar Üniversitesi'nin 09/05/209 tarihli 2019/9 sayılı Atadek Toplantısı'nda görüşülmüş olup 20199/2 karar numarası ile tıbbi etik açısından uygun bulunmuştur. 